\title{
Perancangan Sistem Kontrol Otomatis Lampu Menggunakan Metode Pengenalan Suara Berbasis Arduino
}

\author{
Adam Faroqi , M.T., Mada Sanjaya WS.,M.Si.,Ph.D, Riyan Nugraha \\ Jurusan Teknik Elektro Fakultas Sains dan Teknologi UIN SunanGunungDjatiBandung \\ Jln. A.H.Nasution 105 Bandung 40614 INDONESIA \\ adamfaroqi@yahoo.com,madasws@gmail.com,1riyannugraha4991@gmail.com
}

\begin{abstract}
Abstrak - Perkembangan teknologi saat ini sangat bermanfaat bagi kehidupan banyak orang. Semua aspek kehidupan dapat memanfaatkan teknologi sesuai dengan bidang yang dibutuhkan, termasuk kendali rumah. Dari berbagai penelitian yang telah dilakukan diketahui bahwa sinyal suara dapat juga digunakan untuk berinteraksi dengan komputer, sehingga interaksi tersebut dapat berjalan lebih alami. Penelitian yang dilakukan dengan menggunakan data sinyal suara ini umumnya disebut dengan pemrosesan sinyal suara (speech processing).Penelitian ini bertujuan untuk membuat sistem yang dapat mengenali suara dalam bentuk kalimat agar kedepannya bisa digunakan dalam teknologi listrik. Proses pengolahan suara pun perlu melawati beberapa proses seperti: sampling, ektraksi dan pembelajaran. Dengan proses ekstraksi suatu sinyal suara dapat diketahui karakteristiknya. Terdapat beberapa macam metode ekstraksi ciri yang biasa digunakan, tetapi pada penelitian kali ini menggunakan metode Linear Predictive Coding (LPC). LPC digunakan karena sistem ekstraksinya yang mengadopsi sistem pendengaran manusia sebagai filter pengambilan informasi. Kemudian proses pembelajaran dan pengenalan suara sendiri akan dilakukan oleh Adaptive Neuro Fuzzy Interference System (ANFIS) karena kemampuannya yang bisa melakukan analisis probabilitas dan kemudian menghasilkan respon sesuai dengan parameter. Proses pengenalan suara untuk mengenali kalimat diawali dengan proses perekaman yang akan dijadikan data latih sebanyak 20 buah. Dari hasil uji coba, hasil ekstraksi dengan 4 ciri mempunyai akurasi paling kecil dengan 60\% - 70\%, sedangkan dengan 5 ciri akurasinya 60\% - 80\% dan 6 ciri menghasilkan akurasi yang sama yaitu $70 \%$ - 80\%. Hasil identifikasi secara secara real time dengan 2 orang sebagai pengujiannya menghasilkan akurasi $60 \%$ pada pengujian orang pertama dan $70 \%$ pada orang kedua untuk pengujian dengan 4 ciri. Analisa waktu respon dengan ciri adalah ciri lebih sedikit akan mempercepat respon matlab dan analisi dengan banyak ciri akan melambatkan waktu respon.
\end{abstract}

Kata kunci :Kontrol Otomatis Lampu, Pengenalan Suara, Ekstraksi, LPC, ANFIS

\section{Pendahuluan}

\subsection{Latar Belakang}

Keberadaan teknologi adalah untuk mempermudah pekerjaan manusia dengan adanya teknologi pekerjaan yang manusia sebelumnya dikerjakan dalam waktu lama dan membutuhkan banyak tenaga, maka pekerjaan ataupun aktivitas kita menjadi lebih cepat dan dapat menghemat tenaga kita. Semuanya dapat diselesaikan dengan lebih effisien. Salah satunya dengan berkembangnya teknologi elektronika. Dengan elektronika maka dapat dibuat peralatan yang dapat digunakan untuk membantu pekerjaan sesuai yang kebutuhan kita.

Di dalam dunia modern yang meng-edepankan kenyamanan dan kecepatan, sistem yang bekerja secara otomatis akan semakin banyak. Otomatis sering kali diartikan sebagai tidak menggunakan tenaga manusia. Pengertian otomatis dapat disimpulkan seperti, teknik dan peralatan yang digunakan untuk melakukan operasi atau kontrol ataupun kondisi dikendalikan atau dioperasikan secara otomatis. Di dunia industri, sistem otomatis juga sangat diminati karena

TELKA, Vol.2, No.2, November 2016, pp. 106 117

ISSN (e): 2540-9123 
dapat menjamin kualitas produk yang dihasilkan, memperpendek waktu produksi dan mengurangi biaya untuk tenaga kerja manusia.

Untuk mengatasi permasalahan tersebut maka penulis bermaksud merancang sistem kontrol lampu dengan memanfaatkan pengenalan suara .oleh karena itu skripsi ini diberi judul "Perancangan Sistem Kontrol Otomatis Lampu Menggunakan Metode Pengenalan Suara Berbasis Arduino".

\subsection{Tujuan}

1. Menghasilkan suatu alat untuk memudahkan sistem pensaklaran lampu menggunakan pengenalan suara sebagai pengendalinya.

2. Dapat mengetahui keakuratan hasil atau keberhasilan dalam berbicara dalam menghidupkan atau mematikan sebuah lampu.

\subsection{Batasan Masalah}

Batasan masalah dalam penelitian ini adalah :

1. Lampu yang di gunakan adalah 1 buah lampu LED (Light Emitting Diode) 220 volt

2. Menggunakan mikrokontroler Arduino Uno sebagai pengolah data.

3. Suara yang di gunakan adalah suara manusia 2 orang laki laki.

4. Metode yang digunakan adalah metode logika Fuzzy ,LPC (Linear Predictive Coding) dan ANFIS (Adaptive neuro fuzzy inference).

5. Software yang digunakan adalah Matlab

6. Pengujian alat dilakukan oleh 2 orang dan dalam kondisi sepi .

\section{Tinjuauan Pustaka}

\subsection{Teknologi Nirkabel}

Wireless Technology atau teknologi nirkabel, atau lebih sering disingkat wireless adalah teknologi elektronika yang beroperasi tanpa kabel. Wireless technology dapat dimanfaatkan untuk komunikasi, dan pengontrolan misalnya. Untuk komunikasi, dikenal wireless communication yaitu transfer informasi, berupa apapun, secara jarak jauh tanpa penggunakan kabel misalnya ponsel, jaringan komputer nirkabel dan satelit.

Pengontrolan secara jarak jauh tanpa kabel adalah salah satu contoh teknologi nirkabel. Misalnya penggunaan Remot TV, mobil kontrol, dan Remot untuk membuka pintu garasi mobil. Masyarakat sudah akrab dengan teknologi nirkabel. Baik karena masyarakat menggunakan ponsel ataupun karena mulai banyak yang mengakses Internet melalui layanan hotspot.

\subsection{Sistem Kontrol}

Sistem kontrol adalah proses pengaturan ataupun pengendalian terhadap satu atau beberapa besaran (variabel, parameter) sehingga berada pada suatu harga atau dalam suatu rangkuman harga (range) tertentu. Di dalam dunia industri, dituntut suatu proses kerja yang aman dan berefisiensi tinggi untuk menghasilkan produk dengan kualitas dan kuantitas yang baik serta dengan waktu yang telah ditentukan.Otomatisasi sangat membantu dalam hal kelancaran operasional ,keamanan(investasi,lingkungan),(biayaproduksi),mutu produk dll

\subsubsection{Prinsip Pengontrolan Proses}

Ada 3 parameter yang harus diperhatikan sebagai tinjauan pada suatu sistem kontrol proses yaitu :

- Cara kerja sistem kontrol

- Keterbatasan pengetahuan operator dalam pengontrolan proses

- Peran instrumentasi dalam membantu operator pada pengontrolan proses 
Empat langkah yang harus dikerjakan operator yaitu mengukur ,membandingkan, menghitung, mengkoreksi. Pada waktu operator mengamati ketinggian level, yang dikerjakan sebenarnya adalah mengukur process variable (besaran parameter proses yang dikendalikan). Contohnya proses pengontrolan temperatur line fuel gas secara manual, proses variabelnya adalah suhu. Lalu operator membandingkan apakah hasil pengukuran tersebut sesuai dengan apa yang diinginkan. Besar proses variabel yang diinginkan tadi disebut desired set point. Perbedaan antara process variabel dan desired set point disebut error. Dalam sistem kontrol suhu di atas dapat dirumuskan secara matematis:

Error $=$ Set Point - Process Variabel

Process variabel bisa lebih besar atau bisa juga lebih kecil daripada desired set point. Oleh karena itu error bisa diartikan negatif dan juga bisa positif.

\subsubsection{Sistem Kontrol Otomatis}

Suatu sistem kontrol otomatis dalam suatu proses kerja berfungsi mengendalikan proses tanpa adanya campur tangan manusia (otomatis). Ada dua sistem kontrol pada sistem kendali/kontrol otomatis yaitu :

\section{A. Open Loop}

Suatu sistem kontrol yang keluarannya tidak berpengaruh terhadap aksi pengontrolan. Dengan demikian pada sistem kontrol ini, nilai keluaran tidak di umpan-balikkan ke parameter pengendalian.

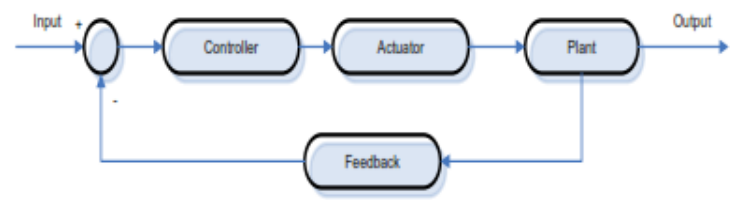

Gambar 1 Diagram Blok Sistem Pengendalian Loop Terbuka

\section{B. Close Loop}

Suatu sistem kontrol yang sinyal keluarannya memiliki pengaruh langsung terhadap aksi pengendalian yang dilakukan. Sinyal error yang merupakan selisih dari sinyal masukan dan sinyal umpan balik (feedback), lalu diumpankan pada komponen pengendalian (controller) untuk memperkecil kesalahan sehingga nilai keluaran.

Sistem semakin mendekati harga yang diinginkan.Keuntungan sistem loop tertutup adalah adanya pemanfaatan nilai umpan balik yang dapat membuatrespon sistem kurang peka terhadap gangguan eksternal dan perubahan internal pada parameter sistem.Kerugiannya adalah tidak dapat mengambil aksi perbaikan terhadap suatu gangguan sebelum gangguan tersebut mempengaruhi nilai prosesnya.

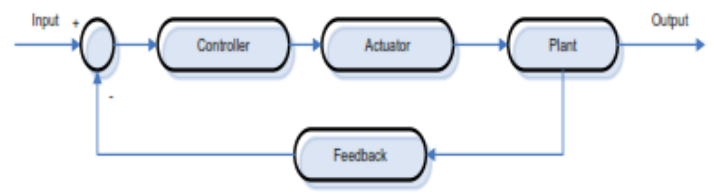

Gambar 2 Diagram Blok Sistem Kontrol Tertutup

\subsection{Pengenalan Suara}

Pengenalan suara (voice recognition atau dikenal juga sebagai speech recognition, computer speech recognition) adalah suatu proses mengubah sinyal suara ke kalimat text[14]. Teknik 
tersebut dikembangkan sebagai sistem memungkinkan komputer untuk menerima masukan berupa kata yang diucapkan. Teknologi ini memunginkan suatu perangkat untuk mengenali dan memahami kata - kata yang diucapkan dengan cara digitalisasi kata dan mencocokkan sinyal tersebut dengan suatu pola tertentu yang tersimpan dalam suatu perangkat.

Kata-kata yang diucapkan diubah bentuknya menjadi sinyal digital dengan cara mengubah gelombang suara menjadi sekumpulan angka yang kemudian disesuaikan dengan kode-kode tertentu untuk mengidentifikasikan kata-kata tersebut. Hasil dari identifikasi kata yang diucapkan dapat ditampilkan dalam bentuk tulisan atau dapat dibaca oleh perangkat teknologi sebagai sebuah komando untuk melakukan suatu pekerjaan. Pengenalan ucapan dalam perkembangan teknologinya merupakan bagian dari pengenalan suara (proses identifikasi seseorang berdasarkan suaranya). Pengenalan suara sendiri terbagi menjadi dua, yaitu pengenalan pembicara (identifikasi suara berdasarkan orang yang berbicara) dan pengenalan ucapan (identifikasi suara berdasarkan kata yang diucapkan).

\subsection{Linear Predictive Coding (LPC)}

Ciri sinyal ucapan sangat berguna untuk sistem pengenalan suara. Salah satu metode yang digunakan untuk prose ektraksi ciri adalah Linear Predictive Coding (LPC). Metode tersebut adalah pemodelan suara yang didasarkan pada teori bahwa suara manusia dibentuk dari getaran sinyal sederhana, yang dihasilkan oleh bergetarnya laring pada rongga tenggorokan.

Teknik ini didasarkan pada fakta bahwa karakteristik suara manusia dapat direpresentasikan dengan menggunakan beberapa parameter matematika sederhana. Ide dasar Linear Predictive Coding adalah sinyal, yang mana pada waktu n dan s(n) dapat diperkirakan sebagai kombinasi linear dari p sinyal sebelumnya. Hal ini dapat direpresentasikan dengan menggunakan persamaan berikut:

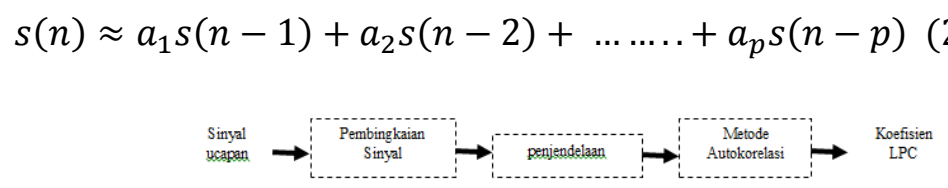

Gambar 3 Blok diagram analisis LPC

\subsection{Logika Fuzzy}

Logika Fuzzy merupakan seuatu logika yang memiliki nilai kekaburan atau kesamaran (fuzzyness) antara benar atau salah. Dalam teori logika fuzzy suatu nilai bias bernilai benar atau salah secara bersama. Namun berapa besar keberadaan dan kesalahan suatu tergantung pada bobot keanggotaan yang dimilikinya. Logika fuzzy memiliki derajat keanggotaan dalam rentang 0 hingga 1. Berbeda dengan logika tegas yang hanya memiliki dua nilai 1 atau 0. Logika fuzzy digunakan untuk menterjemahkan suatu besaran yang diekspresikan menggunakan bahasa (linguistic), misalkan besaran kecepatan laju kendaraan yang diekspresikan dengan pelan, agak cepat, cepat, dan sangat cepat.

\subsection{Microcontroler Arduino UNO}

ATMega328 adalah mikrokontroller keluaran dari atmel yang mempunyai arsitektur RISC (Reduce Instruction Set Computer) yang dimana setiap proses eksekusi data lebih cepat dari pada arsitektur CISC (Completed Instruction Set Computer. Pada gambar di bawah ini merupakan konfigurasi pin pada Atmega328. 


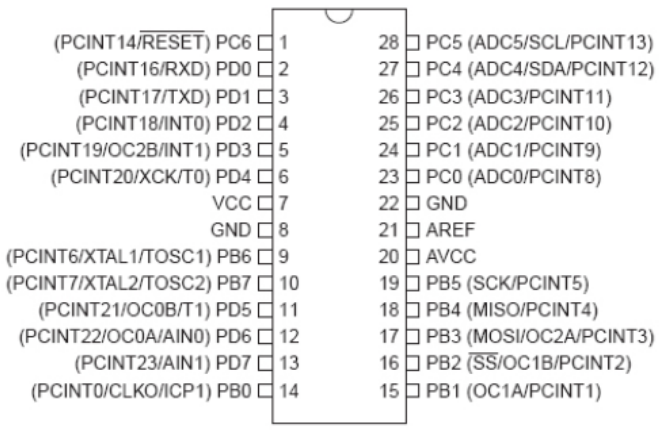

Gambar 4. Konfigurasi PIN Atmega 328

\subsection{Sensor Optocopler}

Optocoupler adalah suatu piranti yang terdiri dari 2 bagian yaitu transmitter dan receiver, yaitu antara bagian cahaya dengan bagian deteksi sumber cahaya terpisah.Biasanya Optocoupler digunakan sebagai saklar elektrik, yang bekerja secara otomatis. Pada dasarnya Optocoupler adalah suatu komponen penghubung (coupling) yang bekerja berdasarkan picu cahaya optic. Optocoupler terdiri dari dua bagian yaitu:

1. Pada transmitter dibangun dari sebuah LED (Light Emitting Diode) infra merah. Jika dibandingkan dengan menggunakan LED (Light Emitting Diode) biasa, LED (Light Emitting Diode) infra merah memiliki ketahanan yang lebih baik terhadap sinyal tampak. Cahaya yang dipancarkan oleh LED (Light Emitting Diode) infra merah tidak terlihat oleh mata telanjang.

2. Pada bagian receiver dibangun dengan dasar komponen Photodiode. Photodiode merupakan suatu transistor yang peka terhadap tenaga cahaya. Suatu sumber cahaya menghasilkan energi panas, begitu pula dengan spektrum infra merah. Karena spekrum inframerah mempunyai efek panas yang lebih besar dari cahaya tampak, maka Photodiode lebih peka untuk menangkap radiasi dari sinar infra merah.

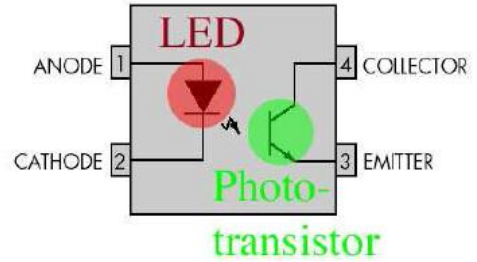

Gambar 5. Optocopler 


\section{Metode Penelitian}

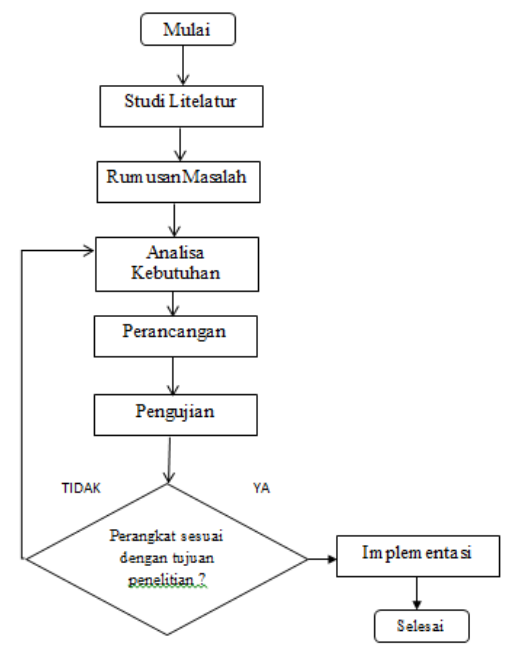

Gambar 6. Bagan tahapan penelitian

\subsection{Studi Litelatur}

1. Studi Literatur

Dimaksudkan untuk mendapatkan sumber referensi-referesnsi yang berkaitan dan mempelajarinya,baik yang terdapat dalam buku,jurnal,dan internet

2. Interview

Tahapan interview dilakukan kepada orang yang sudah ahli maupun yang sudah pernah membuat alat dengan menggunakan mikrokontroler untuk mempermudah melakukan perancangan ,pembuatan dan percobaan alat.

\subsection{Rumusan Masalah}

Mengacu pada studi Litelatur yang telah dijelaskan, maka terdapat beberapa rumusan masalah yang diantaranya adalah :

1. Bagaimana rancangan sistem kontrol otomatis lampu menggunakan metode pengenalan suara berbasis Arduino Uno?

2. Bagaimana keakuratan atau keberhasilan pengenalan suara untuk menghidupkan dan mematikan sebuah lampu?

\subsection{Analisis Kebutuhan}

Kebutuhan yang harus terdapat pada perancangan sisem kontrol otomatis lampu LED 220 volt menggunakan suara, sesuai dengan penyelesaian masalah yang akan dilakukan adalah sebagai berikut:

- Mikrokontroler Arduino Uno

- Optocoupler PC817

- Lampu LED (Light Emitting Diode) 220 volt

- Laptop /Komputer

\subsection{Perancangan}

Pada tahapan ini yang dilakukan adalah membuat perancangan hardware transmitter sesuai apa yang di inginkan dari tujuan penelitian. Dengan menggunakan suara sebagai pengirim perintah ke komputer,microkontroler Arduino Uno, dan Optocoupler dan berikut bagan tahapan analisa perancangan :

ISSN (e): 2540-9123

ISSN (p): 2502-1982 


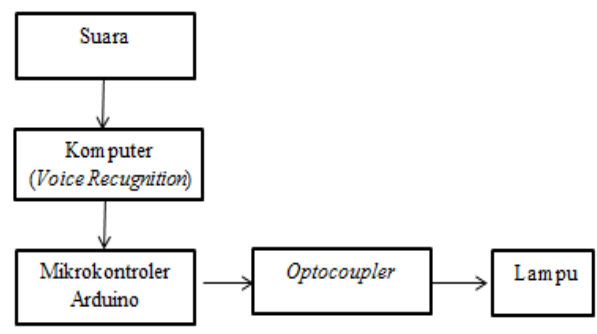

Gambar 7 Bagan Tahapan Perancangan

Ket:

1 Suara : Suara manusia yang berfungsi sebagai pengirim sinyal ke komputer

2 Komputer : Komputer ini sebagai penerima suara dan pengolahan sinyal suara dengan logika Fuzzy

3 Mikrokontroler: Mikrokontrolerberfungsi menerima masukan dari komputer yang kemudian akan mematikan atau menyalakan saklar elektrik

4 Optocoupler : Optocoupler berfungsi sebagai saklar elektrik yang akan memisahkan antara bagian arus DC (mikrokontroler) dengan bagian arus AC

5 Lampu: Lampu yang di gunakan adalah lampu LED 220 volt

Perancangan yang akan dilakukan :

1. Mendeteksi sinyal suara oleh computer

Saat suara dari manusia memancarkan bunyi melalui mulut, komputer akan membaca perintah dari suara tersebut. Setiap kata dan intonasi yang di ucapkan akan dikirim ke komputer melalui udara.

2. Sinyal suara memberikan informasi ke komputer

Pada tahapan ini, perintah suara yang telah terdeteksi oleh komputer, informasi sinyal akan di olah oleh logika fuzzy dan metode LPC (Linear Predictive Coding).

3. Informasi yang telah diolah oleh logika fuzzy dan metode LPC dikirimkan ke Arduino Uno. Pada tahapan ini sinyal yang telah diterima dari komputer, maka sinyal akan diolah oleh mikrokontroler dan setelah itu sinyal siap untuk dipancarkan dan dapat diterima oleh Optocoupler .setelah itu lampu dapat di jalajankan.

\section{Perancangan dan Implementasi}

\subsection{Ektraksi Ciri Linear Predictive Coding (LPC)}

Ekstraksi ciri merupakan proses untuk mendapatkan ciri tertentu dari suatu sample suara. Ciri tersebut direpesentasikan untuk dijadikan sebagai model input-an pada metode pemodelan. Dari hasil dari proses suara kemudian diproses menggunakan metode LPC untuk mendapatkan koefisien cepstral yang merupakan feature yang ingin didapatkan. Langkah - langkah untuk mendapatkan feature tersebut menggunakan LPC dapat dilihat pada gambar 8 .

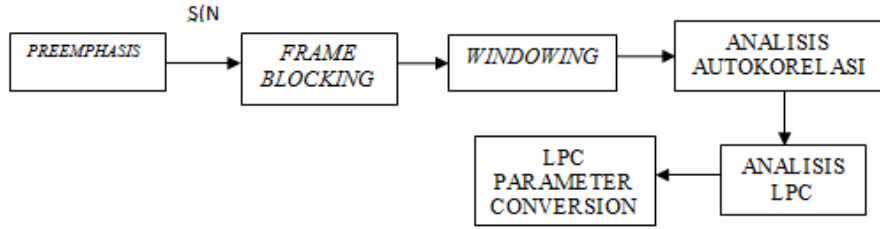

Gambar 8 Blok Diagram Ekstraksi Ciri LPC

ISSN (e): 2540-9123

ISSN (p): 2502-1982 


\subsection{Struktur dan Pemodelan ANFIS}

Pemodelan ANFIS yang digunakan dalam penelitian ini menggunakan ANFIS yang diprogram menggunakan Matlab. Adapun tahapan yang digunakan seperti pada gambar dibawah ini:

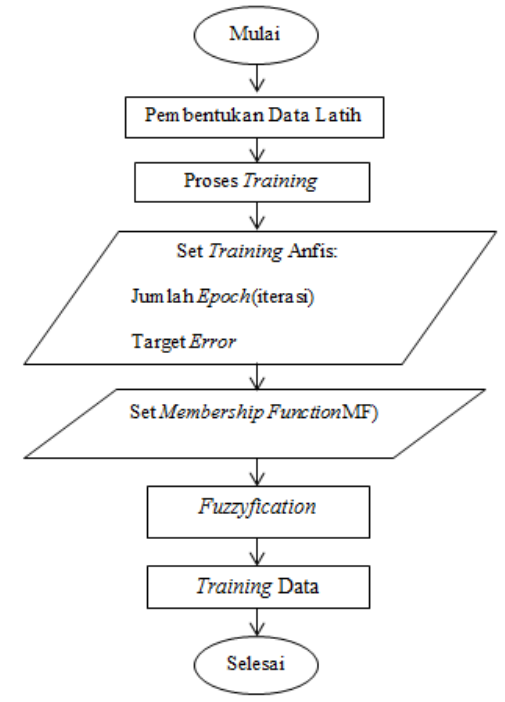

Gambar 9 Pemodelan ANFIS

\subsection{Proses penulisan code program ke mikrokontroler Atmega 328}

Microcontroller Atmega 328 berfungsi untuk mengatur pengiriman sinyal dari hasil pengenalan suara yang telah diseting oleh komuter dan berfungsi untuk mengolah sinyal suara dari analog ke digital (ADC) dan dikirimkan ke rangkaian Optocoupler. Rangkaian Microcontroller Atmega328 dapat dilihat pada gambar 4.10.

Gambar 4.10 Rangkaian Microcontroller Atmega328.

\subsection{Perancangan Hardware Rangkaian Optocoupler}

Rangkaian optocoupler ini sangat sederhana. Tetapi fungsinya sangat sentral pada penelitian ini. Rangkaian optocoupler terdiri beberapa komponen, yaitu : IC MOC dan Juga Optotriac. Fungsi MOC ini adalah sebagai isolator dengan bagian DC dari rangkaian kendali utama agar tidak terhubung secara langsung ke jaringan AC. Selain sebagai isolator MOC tersebut sebagai antarmuka antara bagian kendali (rangkaian DC) agar dapat berkomunikasi dengan jaringan AC. Sementara Optotriac berfungsi untuk memisahkan antara bagian arus DC (mikrokontroler) dengan bagian arus AC beban. TRIAC berfungsi sebagai penguat arus pada beban AC. Dalam pembuatan rangkaian ouptocopler menggunakan software Eagle 6.5.0. Rangkaian optocoupler dapat dilihat pada gambar 10 . 


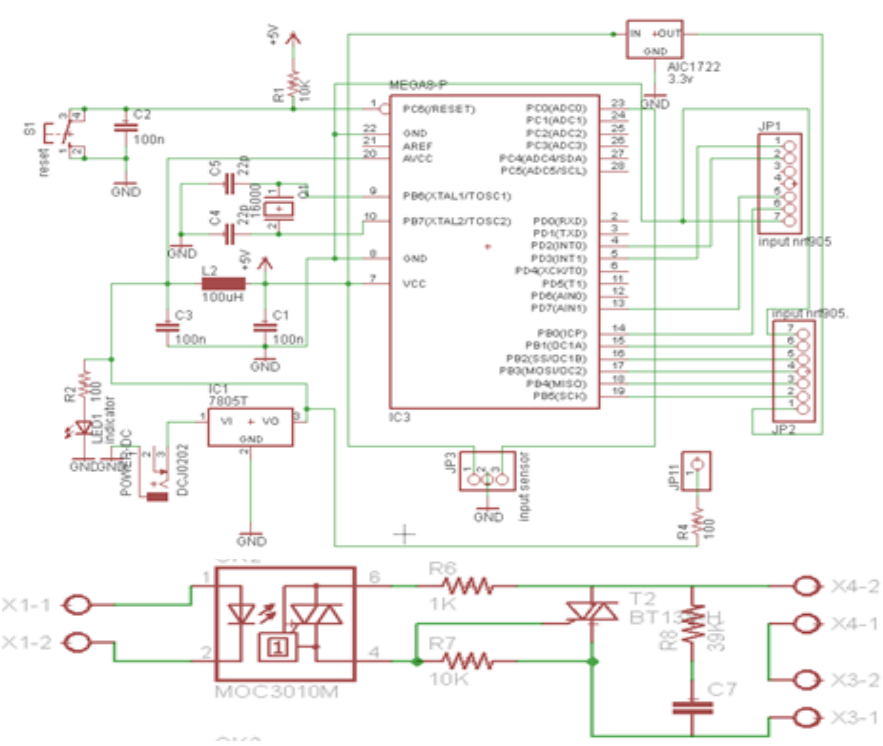

Gambar 10. Skematik Rangkaian Rangkaian Optocoupler

\section{Data dan Hasil Percobaan}

\subsection{Hasil dan Analisa Simulasi Sistem}

Seluruh data suara terdiri dari 30 suara yang didapatkan dari 3 orang. Matriks sampel yang sebelumnya dijadikan data latih dijadikan data uji. Maksudnya agar diketahui kemampuan dan akurasi dari sistem dalam menganalisa data yang telah dipelajari dan juga untuk mencari spesifikasi yang paling akurat dari sistem ini.. Berikut merupakan 2 buah buah sampel kalimat yang dijadikan sampel:

1. Hidup

2. Mati

Untuk input "number MF" yang digunakan adalah 3333 3, sesuai dengan member function yang ada. Lalu untuk tipe MF yang digunakan yaitu gaussmf. Sedangkan untuk output, tipe MF yang digunakan adalah linear. Train FIS optim method dipilih hybrid, error tolerance adalah 0 dan Epochs yang digunakan adalah 10.

\subsection{Hasil Pengujian Dengan 4 Ciri}

Spesifikasi simulasi untuk pengujian adalah sebagai berikut:

1. Data latih yang juga merupakan data uji sebanyak 20 buah

2. MF yang diujikan yaitu gauss

3. Banyak ciri yang diambil berjumlah 4 buah setiap data

4. Pengujian alat di lakukan dalam keadaan sepi

Pada tabel 1 Dapat dilihat bahwa "hidup" mempunyai akurasi paling kecil dengan $60 \%$. Sedangkan "mati" mempunyai akurasi yang paling besar yaitu $70 \%$. Dengan spesifikasi seperti diatas tadi sistem ini secara keseluruhan mempunyai akurasi sebesar $65 \%$. 
Tabel 1 Hasil Pengujian dengan 4 Ciri Tipe Gauss

\begin{tabular}{|c|c|c|c|}
\hline Kata Perintah & Benar & Salah & Akurasi \\
\hline Hidup & 6 & 4 & $60 \%$ \\
\hline Mati & 7 & 3 & $70 \%$ \\
\hline Total & 13 & 7 & $65 \%$ \\
\hline
\end{tabular}

\subsection{Hasil Pengujian dengan 5 ciri}

Spesifikasi simulasi untuk pengujian adalah sebagai berikut:

1. Data latih yang juga merupakan data uji sebanyak 20 buah

2. MF yang diujikan yaitu gauss

3. Banyak ciri yang diambil berjumlah 5 buah setiap data

4. Pengujian alat di lakukan dalam keadaan sepi

Pada tabel 2 Dapat dilihat "hidup" mempunyai akurasi paling kecil dengan 60\%. Sedangkan "mati" mempunyai akurasi yang lebih besar yaitu $80 \%$. Dengan spesifikasi seperti diatas tadi sistem ini secara keseluruhan mempunyai akurasi sebesar $70 \%$.

Tabel 2 Hasil Pengujian dengan 5 Ciri Tipe Gauss

\begin{tabular}{|c|c|c|c|}
\hline $\begin{array}{c}\text { Kata } \\
\text { Perintah }\end{array}$ & Benar & Salah & Akurasi \\
\hline Hidup & 6 & 4 & $60 \%$ \\
\hline Mati & 8 & 2 & $80 \%$ \\
\hline Total & 14 & 6 & $70 \%$ \\
\hline
\end{tabular}

\subsection{Hasil Pengujian dengan 6 ciri}

Spesifikasi simulasi untuk pengujian adalah sebagai berikut:

1. Data latih yang juga merupakan data uji sebanyak 20 buah

2. MF yang diujikan yaitu gauss

3. Banyak ciri yang diambil berjumlah 6 buah setiap data

4. Pengujian alat di lakukan dalam keadaan sepi

Dengan spesifikasi seperti diatas hasilnya dapat dilihat pada table 3 Dapat dilihat "Hidup" mempunyai akurasi paling besar dengan 70\%. Sedangkan "Mati "mempunyai akurasi yang sama yaitu $80 \%$. Dengan spesifikasi seperti diatas tadi sistem ini secara keseluruhan mempunyai akurasi sebesar $75 \%$.

Tabel 3 Hasil pengujian dengan 6 ciri tipe Gauss

\begin{tabular}{|c|c|c|c|}
\hline Kata Perintah & Benar & Salah & Akurasi \\
\hline Hidup & 7 & 3 & $70 \%$ \\
\hline Mati & 8 & 2 & $80 \%$ \\
\hline Total & 15 & 5 & $75 \%$ \\
\hline
\end{tabular}

\subsection{Analisa Perbandingan Ciri}

Dari tabel di bawah ini dapat dilihat bahwa akurasi terlihat stabil pada posisi 5 ciri. Dan terlihat bahwa pada keadaan dengan 4 ciri akurasi cenderung menurun sedangkan pada posisi 6 ciri hasilnya tidak jauh berbeda dengan 5 ciri. Dari keadaan tersebut dapat disimpulkan bahwa 
banyaknya ciri MFFCC yang dihasilkan akan mempengaruhi akurasi, namun tidak selamanya karena terlalu banyak jumlah ciri akan membuat sistem kebingungan karena banyaknya titik ciri yang serupa dari tiap sampel suara.

Selain itu juga jumlah ciri pun terpengaruhi oleh lebar frame yang telah dipilih, hal itu dikarenakan pengambilan ciri akan lebih baik apabila dengan ciri yang sedikit akan tetapi tetap bisa mengenali tiap ucapan dengan akurasi yang besar.

Tabel 4 Analisa Perbandingan Ciri

\begin{tabular}{|l|l|l|l|}
\hline Kata Perintah & 4 Ciri & 5 Ciri & 6 Ciri \\
\hline Hidup & $60 \%$ & $60 \%$ & $70 \%$ \\
\hline Mati & $70 \%$ & $80 \%$ & $80 \%$ \\
\hline Total & $65 \%$ & $70 \%$ & $75 \%$ \\
\hline
\end{tabular}

\section{Kesimpulan dan Saran}

\subsection{Kesimpulan}

Dari penelitian "Perancangan Sistem Kontrol Otomatis Lampu Menggunakan Metode Pengenalan Suara Berbasis Arduino " yang telah dilakukan mulai dari data dan pengumpulan data, analisis kebutuhan dalam pembuatan alat, kemudian merancang desain rangkaian optocopler lalu mengimplementasikan perakitan komponen-komponen mikrokontroler, dan membuat program hingga alat dapat bekerja. Kemudian dilakukan pengujian dan analsis. Setelah pengujian dan analisis dilakukan dapat disimpulkan sebagai berikut

1. Setelah dilakukan perancangan pada setiap rangkaian yang dibuat, mulai dari rangkain optocopler, rangkaian atmega328, setelah rangkaian tersebut diujikan dapat disimpukan bahwa alat-alat tersebut dapat bekerja.

2. Sistem dengan ANFIS dapat digunakan untuk pengenalan suara. Terbukti dengan keakurasian sistem ini antara 60\%-80\% dari 20 buah data latih.

3. Hasil analisa performa sistem:

a. Hasil ekstraksi dengan 4 ciri mempunyai akurasi paling kecil dengan $60 \%-70 \%$. Sedangkan dengan 5 ciri akurasinya $60 \%$ - 80\% dan 6 ciri menghasilkan akurasi yang sama yaitu $70 \%-80 \%$.

b.Kombinasi terbaik antara sistem ini yaitu pada 4 ciri ekstraksinya yang digunakan yaitu tipe Gauss.

c.Pengujian secara real time dengan 2 orang sebagai pengujiannya menghasilkan akurasi $60 \%$ pada pengujian orang pertama dan $70 \%$ pada orang kedua.

d.Analisa waktu respon dengan ciri yaitu ciri lebih sedikit akan mempercepat respon matlab dan ciri lebih banyak akan melambatkan waktu respon.

\subsection{Saran}

Harapan penulis dimasa mendatang hasil dari "Perancangan Sistem Kontrol Otomatis Lampu Menggunakan Metode Pengenalan Suara Berbasis Arduino" yang telah dilakukan dapat dijadikan sebagai tolak ukur untuk dikembangkan dikemudian hari, juga bisa digunakan sebagai referensi bagi pembaca. Jika ingin mengembangkan atau lebih menyempurnakan dari hasil penelitian ini, maka penulis menyarankan seperti :

1. Diharapkan dapat di implementasikan pada peralatan yang lain sehingga dapat mempermudah kinerja manusia

2. Diharapkan dapat menambah jumlah lampu lebih banyak .

3. Meningkatkan keakurasian sistem dengan cara menambah data latih agar hasil identifikasi bisa lebih optimal

4. Proses pembuatan data latih dan pengujian real time menggunakan perangkat yang sama 
5. Menambah jumlah data latih yang didapat dari banyak orang dengan karakteristik suara yang beragam agar hasil pembelajaran semakin baik

\section{Daftar Pustaka}

[1] Fachrudin AN., 2004 "Pengenalan Pengucap Tak Bergantung Teks dengan Metode Vector Quantization (VQ) Melalui Ektraksi Linear Predictive Coding (LPC)”,http://eprints.undip.ac.id/25626/1/ML2F099604.pdf.

[2] Hermawan,AB. , 2011 ," Analisisi Karakteristik Lampu Led Sebagai Lampu Penerang,", Skripsi, Universitas Muhammadiyah Yogyakarta.

[3] Muh. Widyanto Tri Saksono, Achmad Hidayatno, Ajub Ajulian Z, 2011 , "Aplikasi Pengenalan Ucapan Sebagai Pengatur Mobil Dengan Pengendali Jarak Jauh”, http://eprints.undip.ac.id/25361/1/ML2F003519.pdf

[4] Fajar Timang Patiung, Arie.S.M. Lumenta, Sherwin R.U.A. Sompie, 2014 ,” Rancang Bangun Robot Beroda dengan Pengendali Suara", http://www.ejurnal.com/2014/10/rancang-bangun-robot-beroda-dengan.html.

[5] Hisni Zainul Milah. Burhanuddin. Gelar Budiman, 2014, "Desain Dan Implementasi Sistem Kendali Pintu Menggunakan Suara Berbasiskan MikrokontrolerAtmega8535DanTms320c6455",http://digilib.tes.telkomuniversity.ac.id/ind ex.php?option=com_repo\&Itemid=34\&task=detail \&nim=111071094.

[6] A.Winoto,2010,"MikrontrolerAVR ATmega8/16/32/8535 dan Pemrogramannya denganBahasaC", adln.lib.unair.ac.id/.../gdlhub-gdl-sl-2013-fannanyzai-26849-15.-dafta.pdf.

[7] Saputra,FA.,2013,Tentang Pembuatan Robot Sumo, http://fandi.students.uii.ac.id/2013/04/25/11/. 